\title{
Retazos de novela sentimental castellana. Hacia La Princesse de Clèves
}

\author{
Eugenia Fosalba \\ Universitat de Girona - España
}

Cet article passe en revue les auvres qui ont précédé La Princesse de Clèves (1678): le roman sentimental espagnol qui, par le biais de multiples éditions (souvent bilingues) et de traductions, jouit d'un grand succès en France, dès le XVI' siècle et, tout au long du $X V I I$. Afin d'analyser l'utilisation épurée et sophistiquée qu'en fait la Comtesse de La Fayette, l'auteur de l'article relève des traces légères, des procédés littéraires et quelques stratégies narratives caractéristiques de ces lointaines nouvelles qui se sont frayé un chemin dans le contexte du XVII siècle français. Un autre apport remarquable de cette étude a trait à la recherche des sources historiques qui concernent l'amant de la princesse, ainsi qu'à l'interprétation globale et novatrice du chef d'ouvre français permise par les découvertes relatives aux sources.

En este articulo se repasan los precedentes de La Princesse de Clèves (1678) en la novela sentimental española, que a través de múltiples ediciones (a menudo bilingües) $y$ traducciones goza de gran éxito en Francia ya desde el mismo siglo XVI y después a lo largo de todo el XVII. La autora del artículo va espigando huellas leves, recursos literarios $y$ alguna estrategia narrativa fundamental de aquellas lejanas novelitas que se han ido abriendo paso en el nuevo contexto del siglo XVII francés, para analizar la depurada sofisticación con que ahora se emplean por parte de la condesa de La Fayette. Otras aportaciones relevantes de este estudio atañen a la investigación de las fuentes históricas del enamorado de la princesa y la interpretación global y novedosa de la obra maestra francesa gracias a los hallazgos relativos a sus fuentes.

* Grupo de investigación : HUM 2005-02842.

$B H i$, Tome 108, no 2 - décembre 2006 - p. 389 à 420. 
This article reviews the Spanish sentimental novels preceding La Princesse de Clèves (1678), which enjoyed great success in France in its multiple and frequently editions and translations first in the 16 th century and then throughout the $17^{\text {th }}$ century. The author of the article sorts out slight hints, literary resources or basic narrative strategies of those remote novels which were emerging onto the scene within the new context of $17^{h}$ century France so as to analyse the refined sophistication with which those resources were to be employed by the Countess de La Fayette. Other relevant contributions of this study concern the investigation of historical sources for the princess's lover and the comprehensive and innovative interpretation of the French masterpiece thanks to the discoveries related to its sources.

Mots-clés : Roman sentimental - Roman pastoral - Roman maure - Traductions - Littérature française au XVII siècle - Littérature comparée.

El título de la novela de Madame de Villedieu, Galanteries grenadines (1672), trae a la memoria de qué forma fueron apreciados los amores de Abindarráez y Jarifa por los autores de novelas heroico-sentimentales: por Mademoiselle de Scudéry en los ocho tomos de su Almabide (1660-1663) y, especialmente, por nada menos que Madame de Lafayette, en su Zaïde, histoire espagnole (1670), que inauguró el arte de quien escribiría la exquisita Princesse de Clèves (1678).

Claudio Guillén

En este ańo, dominado por el homenaje al cuarto centenario de 1605, propongo aquí un breve aparte en recuerdo de otras contribuciones españolas a la novela universal. Me refiero a la narrativa sentimental, cuyos orígenes, como las fuentes del Quijote, hunden sus raíces en la lectura de entretenimiento de finales del siglo XV y buena parte del XVI, pero cuya trayectoria discurre a menudo en Europa al margen del legado cervantino. La traducción compulsiva al otro lado de los Pirineos de novelas precervantinas como la Cárcel de amor (1492) de Diego de San Pedro deja por ejemplo muy pronto su huella en uno de los cuentos (Nouvelle $X I)$ de L'Heptaméron (1559), si bien la anécdota se reduce a su esqueleto, desaparece la hipérbole sacroprofana del sacrificio de Leriano y se prescinde de alguna estrategia narrativa todavía rudimentaria que, solo mucho tiempo después, la diestra pluma de Mme de La Fayette sabrá desplegar 
en su inmensa potencia novelesca. Tampoco puede desdeñarse la presencia en 1536 del Grimalte y Gradissa (ca. 1495) de Juan de Flores en la versión de Maurice Scève, poeta del círculo de la misma Margarita de Navarra, sobre todo porque solo dos años después verá la luz la primera parte de la novela sentimental francesa, Les angoysses douloreuses qui procedent d'amours, de Hélisenne de Crenne. La novela, una «epistre dedicative... a toutes honnestes dames", arranca del comienzo de la Elegia di Madonna Fiammetta (1344) de Boccaccio, cuya protagonista recuperó Juan de Flores como un personaje más de su ficción para erigirla al final en ejemplo ex contrario de la Gradissa española. A Helisenne de Crenne le sirvió en cambio de punto de partida para narrar la forma en que una dama biencasada se aficionaba a un joven poco recomendable, y le proporcionó asimismo el marco epistolar para la narración de su propio enamoramiento adúltero ${ }^{1}$.

\section{BOCCACIO, JUAN DE FLORES, HÉLISENNE DE CRENNE}

No debería sorprendernos entonces que dos siglos después de su primera aparición en España, la obra de Juan de Flores pudiera constituir un lejano precedente en la extraordinaria decisión que se da al final de una obra maestra como la Princesse de Clèves ${ }^{2}$ (1678), cuando su protagonista, encontrándose viuda y cn la flor de la juventud, rechaza al hombre que ama con todo su ser. Para entender esta renuncia, que en su día levantó una tormentosa polémica recogida por la gaceta Mercure galant, resulta imprescindible desandar la educación sentimental de ésta o de cualquier otra dama exquisita: un primerísimo jalón de su proceso pedagógico pudo ser el fracaso de Grimalte al intentar convencer a Pamphilo de que regresara con Fiometa, porque este hecho sacude la conciencia de Gradissa, quien no duda ahora en echar con cajas destempladas a su pretendiente. No existe ningún otro obstáculo material para su amor salvo la traba espiritual que constituye la novela de amor creada por Boccaccio. El género sentimental consigue de esta manera, con su propio ejemplo, alterar el comportamiento de sus personajes, y en virtud de una extraña paradoja que termina por ahuyentar el amor, suple la experiencia vivida por otra ajena y literaria; es así como se abre camino a la

1. Huérfana de padre, como Mlle de Chartres, y esposada a los once años: en ambas jóvenes la educación queda en manos de la madre, que precipita la boda y pronto falta, por el matrimonio en el caso de Helisenne, y por la boda y su casi inmediata muerte en La Princesse. Afrontan así los embates de la pasión desde una posición de extrema fragilidad.

2. Ya lo notó Caridad Martínez (1992: 18-20). 


\section{BULLETIN HISPANIQUE}

novela de análisis, abismando la conciencia femenina en los meandros de los propios razonamientos, de lógica y finura implacables, aun orientados por el más irracional terror.

De todas formas, un destacable eslabón intermedio entre la renuencia de Gradissa y la de Mme de Clèves hubo de ser la desdichada experiencia de Helissene de Crenne. Y una diferencia sustancial entre el modelo español, que mezcla con las suyas las criaturas boccaccianas, y las Angoysses douloureuses radica precisamente en el galán, que en la novela francesa está inspirado en un modelo al parecer real ${ }^{3}$, el del joven Guenelic, muy distante en su condición moral del esforzado Grimalte. Una mañana, mirando distraídamente por la ventana, Hélisenne descubrió la figura de un apuesto caballero que llamó muy vivamente su atención, pues le pareció «de tresbelle forme $\&$ selon que ie pouoye coniecturer a sa phisonomie, ie l'estimoys, gracieux $\&$ amyable, il avoit le visage riant, le cheuelure creppe, ung petit blonde, $\&$ sans avoir barbe qui estoit manifeste demonstrance, de sa gentile ieunesse.» La descripción coincide de forma exacta con la morfología que atribuía Gregorio Marañón al tipo del Don Juan, por completo antitética del «verdadero varón» de talla reducida, piernas cortas, rasgos fisonómicos acusados, piel ruda y muy provista de barba y vello: «Nada, por lo tanto, parecido al Don Juan esbelto, elegante, de piel fina, cabello ondulado y rostro lampiño..." ${ }^{4}$ Guenelic es, en efecto, un seductor, y a pesar de su esbeltez, su catadura moral es de la más baja estofa. Cegado por la vanidad es incapaz de callar sus avances -mínimosaunque ello perjudique la dignidad de Hélisenne. De hecho esos avances solo se concretan en la turbación que Guenelic despierta en ella, la torpeza con que se muestra incapaz de esconderle su deseo y que él descubre con regocijo y no tarda en dar a conocer: nada importa que a la acongojada mente de Helisenne acudan oportunos ejemplos literarios de amor destructivo,

3. A raíz de los descubrimientos de Loviot y de M. V.-L. Saulnier, la crítica se ha puesto de acuerdo en aceptar como muy próxima a la verdad de los hechos la primera parte de la novela, que es obra, como puede deducirse de un documento de donación, de «Margueritte de Briet, femme de Philippe Fournel, escuier, seigneur de Crasnes, [de ahí habría tomado el apellido para su seudónimo], et de luy sepparee quant aux biens, demourant à Saint Germain des Prez lez Paris", texto citado por Paule Demats en su estudio introductorio a la obra en (1968: 9). También en este prólogo se baraja la posibilidad de que el nombre de pila del seudónimo estuviera inspirado en la madre de Amadís, lo que no tendría nada de extraño, dado el extraordinario éxito de la novela en Francia, y el comportamiento desinhibido de la princesa al comienzo de la novela, que Juan de Valdés no dudó en afearle en su Diálogo de la lengua.

4. Marañón (1946: 74). 
Helena, Medea, Euríalo y Lucrecia 5 , Lancelot du Lac y la royne Guenièvre, Tristán e Iseo, porque son todos barridos de su mente por el "tresdur assault» de «l'appetit sensuel». Para agravar más la situación y ahondar más vueltas en el torbellino de locura en que se ve inmersa la narradora, las indiscreciones de Guenelic no tardan en llegar a oídos del esposo de Hélisenne y es éste último quien la informa de las mezquinas traiciones de su amigo. Pero la furia del marido no consigue aplacarla y como él mismo reconoce en los escasos momentos en que se compadece de su enfermedad, es en efecto el apetito sensual el responsable de su desvarío, "par ce que ie cognois les premiers mouvements n'estre en nostre puissance» ${ }^{6}$. Resulta curioso que la Princesa de Clèves también los perciba en sí misma desde el principio sin que nadie deba advertírselo ${ }^{7}$ y aunque le resulte imposible ocultar su confusión, es precisamente esta conciencia y el consiguiente control férreo de sus propias pasiones el que le ayudará a sacar fuerzas de flaqueza para sobreponerse y sujetar las riendas de su destino.

5. Vid. Ravasini (2003).

6. Un texto de San Agustín sirvió de punto de partida para la reflexión doctrinal sobre los primeros movimientos, que Aristóteles había definido como la primera manifestación de una pasión. En De Trinitate (XII, 12), se establece un paralelo entre la tentación del paraíso terrestre y las tentaciones que sentimos todos los días. En cuanto el apetito inferior busca llevar la razón hacia un placer prohibido, puede determinarse que empieza la tentación. Acceder a esta solicitud equivale a saborear el fruto prohibido. El placer que uno adquiere con solo el pensamiento del mal es ya reprehensible; sin embargo, esta falta de la razón inferior es menos grave que la de la razón superior capitaneando la mala acción. Para San Agustín, el pecado empieza con la intervención de la razón, inferior o superior. La trayectoria de este pasaje en el pensamiento teológico desde el siglo XII se encuentra excelentemente reseñada por Couture (1962). El concepto llegó a popularizarse tanto que la literatura secular se halla sembrada de referencias a él; cf. Quijote (I, 20): "perdona lo pasado, pues eres discreto y sabes que los primeros movimientos no son en mano de hombre».

7. «Quelque application qu'elle eût à éviter ses regards et à lui parler moins qu'à un autre, il lui échappait de certaines choses qui partaient d'un premier mouvement, qui faisaient juger à ce prince qu'il ne lui était pas indifférent.» Y pocas páginas más adelante, «...elle fit réflexion à la violence de l'inclination qui l'entraînait vers $M$. de Nemours; elle trouva qu'elle n'était plus maîtresse de ses paroles et de son visage...», cito por la edición de Émile Magne (1939: 298 y 303). En sus notas a La Quinta de Florencia, Morros (1998: Parte II, n. 1266) recuerda un pasaje de la Cárcel de amor: los "primeros movimientos no se pueden en los hombres escusar" y otro muy significativo de la Celestina, VII, 1, donde queda patente la opción de controlar ese primer impulso: «Verdad es, pero del pecado lo peor es la perseverancia, que assí como el primer movimiento no es en mano del hombre, assí el primer yerro.» Recuérdese que en la versión más antigua de los amores de Abindarráez y Jarifa se explica que «no hubo primeros movimientos que escusar porque el principio de nuestros amores fue un gusto y deleite fundado sobre bien querer simplemente y sin cautela. Mas después no vino el mal poco a poco sino de golpe y todo junto.» 
Decidir el propio destino. Quizá sea ésta una de las principales causas por las que la novela intimista de la condesa de La Fayette está escrita en tercera persona, porque a fin de cuentas la narradora desestima el yo patético de la epístola heroidiana, ese lamento femenino al que las Lettres portugaises (1669) habían vuelto a dar vigencia en fechas muy próximas a los primeros esbozos de La Princesse ${ }^{8}$. De acuerdo entonces con el tono elegíaco del género en que está escrita la primera parte -la más auténtica y autobiográfica- de las Angoysses douloureuses ${ }^{9}$, no está al alcance de Hélisenne sujetar su desaforado deseo, ni dejar de hundirse cada vez más en la miseria moral y física de su obsesión, con alguna intercadencia en el intento fallido de darse muerte. Así termina imponiéndose el recogimiento de la dama en la alcoba para convalecer de sus delirios, y después, por orden de su celoso cónyuge, la prisión en uno de los châteaux, Cabasus, donde decide escribir su autobiografía. El objeto -contradictorio y por tanto verosímil- es avisar a las damas de los sufrimientos del amor, y esperar que su escritura llegue a manos de Guenelic para que acuda en su rescate. No cabe duda de que Hélisenne hizo tan brutta figura a causa de su indisimulable deseo expuesto a humillación pública por el petimetre, que pudo convertirse en un excelente revulsivo para otras conciencias femeninas, como la de la Princesse, no en balde creada por otra mujer, ésta sí real, a quien no por casualidad el amor le parecía "une chose incommode» ${ }^{10}$, y en perfecta coherencia con ese deseo de sosiego, vivió atrincherada en un plácido matrimonio de conveniencia ${ }^{11}$.

8. El 16 de Marzo de 1671, Mme de Sévigné escribe a su hija: «Je suis au désespoir que vous ayez eu Bajazet par d'autres que par moi. C'est ce chien de Barbin qui me hait parce que je ne fais pas des Princesses de Clèves et de Montpensier.» Este comentario, más un privilegio encontrado por Émile Magne, confirman que poco después de la publicación de Zaïde, Mme de La Fayette trabajaba en un nuevo texto (primer bosquejo de la Princesse de Clèves) del que Barbin se había asegurado, por adelantado, los beneficios editoriales (Magne: 24). Craveri recuerda por su parte algo parecido, desde un punto de vista disntinto: «Adelantándose a la Princesse de Clèves, el amable y escéptico Guilleragues enseñaba a las mujeres a usar la sinceridad como un arma y adueñarse de su propio destino. Sin embargo, a diferencia de la heroína de Madame de La Fayette, la monja portuguesa no renuncia a vivir el amor por miedo al desengaño..." (2003: 157). Sobre las Heroidas en otras obras sentimentales, principalmente españolas, vid Brownlee (1990).

9. Gustave Reynier ofrece un análisis somero de cada parte en su clásico estudio (1971).

10. Sobre las causas más psicológicas que estrictamente literarias del rechazo de la princesa, vid. de Jean Cordelier (1975: 43-57). No me ha sido posiblc consultar, cn cambio, Claude Vigée (1960: 723-754).

11. Acerca de su relación con el sarcástico La Rochefoucauld, tan fecunda literariamente, y que avanzó hacia una profunda intimidad mantenida en el terreno de la amistad, comenta, entre otras cosas, Bernard Pingaud (1997: 40): "Limportant est que cette liaison entre 


\section{TRASFONDO hISTÓRICO DE LA PRINCESSE DE CLEVVES}

También el amado de la princesa de Clèves es un personaje tomado de la realidad: el Duc de Nemours, Jacques de Savoye (1531-1585), hijo de Philippe de Savoye y de Charlotte d'Orléans-Longueville, caballero muy famoso en su tiempo por su belleza y atractivo incomparables. Pero no es extraño que personajes del pasado asomen a la obra de Marie-Madeleine Pioche de la Vergne, pues la novela tiene una acusada voluntad historicista y por ello recrea gracias a los testimonios que le ofrece la tradición de las memorias el ambiente mundano de la corte de Henri II $^{12}$. La obra da comienzo con una descripción piramidal y estática de la corte francesa, con el Rey a la cabeza, para pasearse a continuación, como en la écfrasis de un bajorrelieve, por una figura dominante como la de la Duchesse de Valentinois y distinguirla con el título de nobleza que le había concedido su regio amante. No es casual que la autora se detenga inmediatamente después del rey en esta madura y bella dama, pues era famoso el uso eficaz y cruel que hacía de su acceso directo a la alcoba real, y así, en una corte dividida entre los partidarios de los Guise y los del connestable de Montmorency, ambos partidos la temían y se disputaban su favor. Solo después de mencionar a Diane de Poitiers y de momento solo en relación a ella («La présence de la reine autorisait la sienne»), se demora la pluma de Marie-Madeleine en la reine, esposa del rey («... la politique l'obligeait d'approcher cette duchesse de sa personne, afin d'en approcher aussi le roi»), y el lector se ve obligado a deducir que esta nueva figura femenina es Catalina de Medici. Salvo en el caso de la amante del rey (y antes, favorita de su padre, François I) se suele evitar el nombre propio y señalar a cada personaje por el título que ostenta; el orden de su aparición queda determinado por la telarańa de poder que se teje en torno a la cúspide de la jerarquía. A continuación van apareciendo el Rey de Navarra (Antoine de Bourbon), Madame (que era la hermana del rey, Marguerite de France, duchesse de Berry), la reine dauphine (Marie Stuart, reina de Escocia, casada con François de Valois, dauphin de Francia), el chevalier de Guise (François de Lorraine, «était un prince aimé de tout le monde, bien fait, plein d'esprit, plein d'adresse, et d'une valeur célèbre par

deux êtres qui ont beaucoup de goûts communs, beaucoup de dégoûts aussi, qui portent, à quelques nuances près, le même jugement sur la comédie du monde, sans pourtant cesser de se passioner pour elle, deux êtres malades, désabusés, tristes, qui aspirent à trouver la paix dans une intimité confiante, se place d'emblée sous le signe du repos.»

12. A. H. Chamard y G. Rudler se deben estudios completos sobre el cuadro histórico general y sus fuentes en "Les sources historiques» (1914: 92-131, 289-321). 


\section{BULLETIN HISPANIQUE}

toute Europe»), y el prince de Condé (Louis I de Bourbon, jefe del partido protestante). Entonces se despacha con un par de frases al segundo hijo del duc de Nevers, el prince de Clèves: «était digne de soutenir la gloire de son nom; il était brave et magnifique, et il avait une prudence qui ne se trouve guère avec la jeunesse.» Donde destacan su carácter de segundón y una de sus cualidades, la prudencia, que en la juventud podrá ser muy meritoria pero está muy lejos de resultar atractiva. El vidamo de Chartres, descendiente de la casa de Vendôme, era el único que se podía comparar con el duc de Nemours «si quelqu'un lui eût pu être comparable»: sabremos ya adentrados en los vericuetos de la novela que era un seductor de tomo y lomo, capaz de sobrellevar cuatro amantes a la vez. Sin solución de continuidad -creo que muy intencionada- viene el prolongado elogio del duque de Nemours,

Mais ce prince était un chef-d'œuvre de la nature; ce qu'il avait de moins admirable, c'était d'être l'homme du monde le mieux fait et le plus beau. Ce qui le mettait au-dessus des autres était une valeur incomparable, et un agrément dans son esprit, dans son visage ct dans ses actions que l'on n'a jamais vu qu'à lui seul; il avait un enjouement qui plaisait également aux hommes et aux femmes, une adresse extraordinaire dans tous ses exercices, une manière de s'habiller qui était toujours suivie de tout le monde, sans pouvoir être imitée, et en fin un air dans toute sa personnne qui faisait qu'on ne pouvait regarder que lui dans tous les lieux où il paraissait. Il n'y avait aucune dame dans la cour dont la gloire neêut été flattée de le voir attaché à elle; peu de celles à qui il sétait attaché, se pouvaient vanter de lui avoir résisté, et même plusieurs à qui il n'avait point témoigné de passion, n'avaient pas laissé d'en avoir pour lui. Il avait tant de douceur et tant de disposition à la galanterie quil ne pouvait refuser quelques soins à celles qui tâchaient de lui plaire: ainsi il avait plusieurs maîtresses, mais il était difficile de deviner celle qu'il amait véritablement ${ }^{13}$.

La fuente de este pasaje, como ya advirtió Lalanne en 1891, está en una de las obras de Pierre Bourdeille, sieur de Brantôme, en concreto sus Vies des grands capitaines, donde dedica largas páginas a describir los encantos y las actividades de este ilustre personaje, con tanta alabanza, que no extraña que una gran dama, que detestaba al célebre cronista, dijera de él que iba tan perfumado como sus caballos ${ }^{14}$. Todas las gracias que adornan a Nemours

13. Princesse (1939: 243-244).

14. Vid. Ludovic Lalanne (1891): "Ce prince fut un des plus parfaictz et accomplys princes, seigneurs et gentilzhommes qui furent jamais. Qui l'a veu le peut dire comme moy. Il a esté un très beau prince et de très bonne grâce, brave, vaillant, agréable, aymable et accostable, bien disant, bien escrivant, autant en rithme qu'en prose, s'habillant des mieux, si que tout la court en son temps (au moins la jeunesse) prenoit tout son patron de se bien habiller sur luy; et quand on portoit un habillement sur sa façon, il n'y avoit non plus à redire que quand 
hacen de él galán irresistible: no le faltan las habilidades deportivas y las destrezas propias de la caballería, la forma de vestir única e inimitable, la agilidad al bailar, y como perfecto cortesano renacentista (según las reglas del arte de agradar puestas al día por Faret), domina las artes del lenguaje en la composición de versos y discursos. De todas formas, puede observarse cómo la pluma femenina de Mme de La Fayette amplifica la faceta amorosa al introducir el motivo de la vanidad de las féminas que son requeridas por tan bizarro caballero, pues no había dama en la corte cuya fama no se viera acrecentada de habérsele visto interesarse por ella: «Il n'y avait aucune dame dans la cour dont la gloire n'eût été flatée de le voir attaché à elle; peu de celles à qui il s'était attaché, se pouvaient vanter de lui avoir résisté, et même plusieurs à qui il n'avait point témoigné de passion, n'avaient pas laissé d'en avoir pour lui.» Este jirón de frase amplificado nos pone sobre la pista del elogio de los Abencerrajes inserto en la novelita del mismo título de mediados del siglo XVI, que también Brantôme debía conocer puesto que en la estructura de su texto se siguen las mismas pautas del panegírico de la casta del noble moro ${ }^{15}$. Nada tendría de extraño puesto que el singular abad conocía bastante bien el español y la corte castellana. Reza el texto puesto en boca de Abindarráez: «...la cortesía y servicio de las damas andaba en ellos en su verdadero punto: nunca Abencerraje sirvió dama de

on se façonnoit en tous ses gestes et actions. Il estoit pourveu d'un grand sens et d'esprit, ses discours beaux, ses oppinions en un conseil belles et recepvables. De plus, tout ce qu'il faisoit il le faisoit bien, de si bonne grâce et de si belle adresse, sans autrement se contraindre (comme j'en ay veu qui le voulloient imiter sans en approcher), mais si naïfvement que l'on eust dict que tout cela estoit né avec luy. Il aymoit toutes sortes d'exercises, et si y estoit si universel qu'il estoit parfaict en tous. Il estait très bon homme de cheval et très adroict et de belle grâce, fust on à picquer; ou rompre une lance ou courir bague, ou autre exercice pour plaisir; et pour la guerre, bon homme de pied à combattre à la picque et à l'espée, à la barrière, les armes belles en la main. Il jouoit très bien à la paume, aussi disoit-on les revers de $M$. de Nemours; jouoit bien à la balle, au ballon; sautoit, voltigeoit, dançoit, et le tout avec si bonne grâce, quion pouvoit dire qu'il estoit très parfaict en toutes sortes d'exercices cavalleresques: si bien, qui n'a veu M. de Nemours en ses années guayes, il n'a rien veu; et qui l'a veu, le peut baptiser par tout le monde la fleur de toute chevallerie; et, pour ce, fort aymé de toute le monde et principaliement des dames.", (1895: 164-166).

15. Una traducción manuscrita de la Diana, que llevaba consigo el Abencerraje, más temprana que la primera traducción impresa de Nicolas Colin (1578), se dedicó a la "Tresventureuse Princesse Margueritte de France Royne de Navarre", la que sería repudiada por el Bearnés, a quien Brantôme rindió una adoración sin fisuras hasta la muerte. Hace unos años encontré este manuscrito en la Biblioteca Albertina de Bruselas y atribuí su autoría a Mme de Neuvfy, cuya traducción de la Diana alababa Jean Bertaut en uno de sus sonetos. Vid. Fosalba (1999: 105-111). 
quien no fuese favorescido, ni dama se tuvo por digna deste nombre que no tuviese Abencerraje por servidor». Cito el elogio completo en la versión del Abencerraje que se incluyó a partir de 1561 en las ediciones de la Diana, pues así se dio a conocer en Francia y el resto de Europa:

Soy de los Abencerrajes de Granada, en cuya desventura aprendí a ser desdichado; y porque sepas cuál fue la suya y de ahí vengas a entender lo que se puede esperar de la mía, sabrás que hubo en Granada un linaje de caballeros llamados Abencerrajes: sus hechos y sus personas, ansí en el esfuerzo para la guerra como en prudencia para la paz y gobierno de nuestra república, eran el espejo de aquel reino. Los viejos eran el consejo del rey, los mozos ejercitaban sus personas en actos de caballería, sirviendo a las damas y mostrando en sí la gentileza y valor de sus personas. Eran muy amados de la gente popular y no mal quistos entre la principal, aunque en todas las buenas partes que un caballero debe tener se aventajasen a todos los otros. Eran muy estimados del rey, nunca cometieron cosa en la guerra, ni en el consejo que la experiencia no correspondiese a lo que dellos se esperaba. En tanto grado era loada su valentía, liberalidad y gentileza, que se traía por ejemplo no haber Abencerraje cobarde, escaso, ni de mala disposición. Eran maestros de los trajes, de las invenciones ${ }^{16}$; la cortesia y servicio de las damas andaba en ellos en su verdadero punto: nunca Abencerraje sirvió dama de quien no fuese favorescido, ni dama se tuvo por digna deste nombre que [no] tuviese Abencerraje por servidor ${ }^{17}$. (la cursiva es mía)

Por supuesto que de la moda oriental queda muy poco o nada en la Princesse de Clèves, es una huella casi tan invisible como el rastro de nuestro Abencerraje en el elogio de Nemours, pero no por ello resulta menos relevante, porque de hecho, con la Princesse de Clèves el proceso de depuración del oropel heroico y granadino propio de obras inabarcables como Almahïde (1660-63) ${ }^{18}$ llega a su culminación. Los trazos, por tanto, son muy leves, pero nada desdeńables. Por otro lado, el aura mítica del legendario linaje musulmán debía haber arraigado con fuerza en la fantasía francesa cuando un poeta ansioso por llamar la atención como Bensserade invocaba la consonancia de su apellido para vanagloriarse de proceder de

16. Recuérdese el doble sentido de la palabra invención: juego de ingenio verbal y también traje, disfraz.

17. Fosalba (1990: 12).

18. Donde también se injertan en su trama atomizada de relatos secundarios y enmadejada según el modelo griego, las tertulias de L'Astrée, a su vcz pasaticmpo conversacional en tiempos de Mme de Rambouillet. De todas formas, la obra no obtuvo un gran éxito, el público ya estaba cansado de las tramas larguísimas con numerosas historias menores difíciles de recordar, descripciones interminables y discusiones sin fin sobre cuestiones de amor. Vid. el completo estudio de Jerome W. Schweitzer (1939), algo antiguo pero todavía muy útil. 
tan ilustre familia granadina ${ }^{19}$. Es posible que Voiture, el "Rey Chiquito» del salón azul, aludiera irónicamente a él cuando escribía a Mme de Rambouillet, fingiéndose celoso: «Mademoiselle, je ne sais pas qui sont les abencerrages que vous me préférez. Mais j'imagine que ne sont point nés à Grenade, non plus que moi.... ${ }^{20}$. Su recuerdo siguió muy vivo a lo largo del siglo XVII pues todavía en 1685 desfiló en Versailles y en presencia del Rey Sol un espléndido carrusel con dos cuadrillas opuestas que representaron a las dos familias rivales más famosas de la Granada inventada por Pérez de Hita, los Abencerrajes y los Cegríes $^{21}$, y los caballeros de cada bando cambiaron sus nombres de príncipes o de grandes señores por los de los héroes de las Guerras civiles. La brillante journée, ou Carrousel des galants Maures, título con el que se anunciaba la fiesta, consagró, a decir de Festugière, «l'intime association dès lors opérée dans l'opinion générale entre l'idée de galanterie et celle que l'on se faisait des Mores andalous» ${ }^{22}$. Aunque, en verdad, dicha identificación entre galantería y nobleza granadina ya se había fraguado mucho tiempo antes.

Hay algún otro eco en La Princesse, vago, pero muy reconocible: por ejemplo, cuando el Príncipe de Clèves encuentra a su esposa, ese día pálida y yacente, tan sumamente triste, que se queda sorprendido. Entonces se filtra en la novela una frase tan emblemática del Abencerraje como: "Qu'avez -vous, madame, lui dit-il. Il me paraît que vous avez quelque autre douleur que celle dont vous vous plaignez? ${ }^{23}$ No debería sorprender demasiado que en un

19. Cuenta la anécdota Tallemant des Réaux en una de sus Historiettes que permanecieron manuscritas hasta bien entrado el siglo XIX: una vez le pilló un combate en el mar, adonde seguía al duc de Brezé, su mecenas, «mais il desmentit bien le sang des Abencerrages, dont il se disoit issû», pues su máxima preocupación era: «Helas!» s'escriat-il, «où est-ce donc que je me fourreray?» (1961: 494). El mismo autor menciona a dos personajes más que se relacionan con los Abencerrajes: un morisco, Alphonse López, que llegó a París hacia 1604, con el objeto al parecer de establecer una alianza secreta en Francia contra la tiranía de Madrid. Decía que descendía de los Abencerrajes de Granada (I, 315). Y también alude en tono de burla a Montbrun: «...il s'avisa d'aller faire fanfare tout seul à la Place Royale; car il n'y eut que luy qui allast faire comme cela l'Abencerrage» (II, 363).

20. Voiture (I, 240), citado por Cazenave (1925: 605). Vid. la presencia en Francia de otros eventos festivos inspirados en las Guerras civiles en el Traité des tournois... de Menestrier (1669).

21. Aunque dichos Cegríes no fueron nunca un linaje aristocrático sino que el «apelativo zegrii, como explica Luis Seco de Lucena, «alude al hombre de frontera y lo tuvieron algunos jefes de las milicias africanas que estaban al servicio de los reyes granadinos, probablemente por causa de sus actividades militares fronterizas", (1963: 35-36).

22. Festugière (1944: 145-183, esp. 149).

23. Princesse (1939: 348). En el Abencerraje la pronuncia Rodrigo de Narváez al observar 
momento de intimidad entre los distantes esposos, se deslizara de pronto el recuerdo de una escena conciliadora de la obra española: cuando, tras una encarnizada lucha, y mientras cabalga junto al cautivo Abindarráez, Rodrigo de Narváez cree adivinar en la aflicción del noble moro alguna pena más honda que la de verse derrotado.

Y no debería sorprender porque de hecho ya en el proceso de creación de Zaïde (1670-1671), cuya lectura apasionó al siglo siguiente ${ }^{24}$, el mismo texto estaba presente, sin necesidad de compulsarlo constantemente, como si hubiera sido leído y después olvidado. Segrais pudo fijar la dispositio y proporcionarle la documentación histórica precisa para su vuelta a la mitificada reconquista española ${ }^{25}$ : al tratarse de una obra situada fuera del contexto de la decadente corte nazarí, los detalles escenográficos que en Almahïde ocupaban cientos de páginas quedaban descartados; los pormenores militares, duelos, viajes y navegaciones se redujeron de grado a la mínima expresión descriptiva; si se tropezaba con una fiesta o unos esponsales árabes nada se especificaba acerca de trajes o decorados salvo lo imprescindible. También es posible que La Rochefoucauld se ocupara de darle ciertos retoques estilísticos a su prosa. Así Mme de La Fayette pudo concentrarse sobre todo en la elaboración psicológica. Y en la apertura de la obra se percibe, en efecto, esa empatía que el Abencerraje había hecho célebre en la Diana, donde los pastores también gustaban comunicarse sus querellas en el placer de la conversación. I lama la atención el encuentro entre

la profunda tristeza de Abindarráez al ser vencido. Rodrigo sospecha que un caballero tan valiente no puede suspirar por haber sido capturado, sino que otra pena más honda es la causa de su melancolía: «Acordábasele de lo que le había visto hacer; parescíale demasiada tristeza la que llevaba para un ánimo tan grande, y porque también se juntaban a esto algunos sospiros que daban a entender más pena de la que se podía pensar que cupiera en hombre tan valiente, y queriéndose informar mejor de la causa desto, le dijo: 'Caballero, mira que el prisionero que en la prisión pierde el ánimo, aventura el derecho de la libertad, y que en las cosas de la guerra se han de recibir las adversas con tan buen rostro que se merezca, por esta fuerza de ánimo, gozar de las prósperas. Y no me paresce que estos sospiros corresponden al valor y esfuerzo que tu persona ha mostrado, ni las heridas son tan grandes que se aventure la vida, la cual no has mostrado tener en tanto que por la honra no dejases [de] olvidalla. Pues si otra ocasión te da tristeza, dímela, que por la fe de caballero te juro que se use contigo de tanta amistad que jamás te puedas quejar de habérmelo dicho'», Fosalba (1990: 9-10).

24. Zaïde se reeditó siete veces en París hasta fines del siglo XVIII (1672, 1699, 1705 , $1715,1761,1780)$ y tres veces cn Amstcrdam $(1700,1705,1715)$.

25. El nombre y ciertas particularidades de la vida de la heroína las tomó de Pérez de Hita, pero los hechos de orden político y militar de la Histoire générale d'Espagne, aparecida en Lyon en 1587. Véanse los excelentes resúmenes de las obras europeas del género, junto a sus fuentes más relevantes, que ofrece Carrasco Urgoiti (1956). 
Gonsalve y Alphonse en las playas de Tarragona, cuando la tristeza del conde de Castilla llena de curiosidad y toca el corazón resignado del segundo, quien decide brindarle su hospitalidad, dando pie así al relato retrospectivo de sus historias en el marco narrativo de la amistad. En otro momento, el motivo del brazalete de cabellos, prenda de amor también presente en l'Astrée (16071628) -moda que influyó o quizás empezó a su vez en la sofisticación con que se tradujo el "cordón de seda verde y cabellos» de la Diana-condensa en una sola escena el amor por momentos incomunicable de los protagonistas ${ }^{26}$. Tan incomunicable como la pasión violenta de Nemours y la princesa, que no están separados por la raza o el idioma, pero su amor solo puede manifestarse de forma oblicua y termina por concretarse en la pura ensoñación ${ }^{27}$.

Si los cronistas de su tiempo dan cuenta ante todo del prestigio militar de Nemours, (no solo Brantôme, también Agrippa d'Aubigné, Michel de Castelnau, Jacques de Thou, o La Popelinière, entre otros), el aura mítica que da de lleno en la novela escrita un siglo después de su muerte se debe sobre todo a su faceta cortesana de galanteador. Algo parecido podría decirse, salvando las distancias, de los Abencerrajes, cuya actividad belicosa en la propia Granada fue tan beneficiosa para los reyes castellanos, que muy probablemente por esta razón las crónicas y después la literatura escogió ensalzarlos como linaje dotado de gran atractivo, en un proceso de idealización que arranca en las fuentes históricas, y también respecto de ellas. Ambas obras, El Abencerraje y La Princesse, tienen así en común el proceso de sublimación de sus protagonistas masculinos, con raíces de historicidad inequívoca. Mme de La Fayette se inspira en la moda memorialista para recrear el ambiente mundano de la corte francesa que la había precedido en un siglo; pero vale recordar aquí que la inserción de una anécdota ficticia trazada sobre un trasfondo histórico fue precisamente una de las aportaciones del Abencerraje a la novela sentimental, y años después, de su secuela de inmenso éxito en Francia ${ }^{28}$. Lo cierto es que la prosa de Ginés Pérez de Hita

26. Ya analicé con algún detalle las huellas del Abencerraje en esta obra en Fosalba (1994: 260-265).

27. Como ejemplo de comunicación oblicua podría recordarse la maravillosa escena de la sustracción del retrato, pero cualquiera puede valer; del amor al que solo se le permite sobrevivir en la psique de la Princesa, la bella escena nocturna del pabellón de Coulommiers donde la dama trenza la cinta de colores de su amado en una caña de indias que le había pertenecido y contempla a la luz de un candelabro su imagen en los cuadros con que decoró la estancia; cuando oye un ruido en el exterior y vislumbra al duque oculto en el jardín observándola intensamente, huye adentrándose en las habitaciones de la casa.

28. De la primera parte de 1595, se conservan desde los ańos 1597 y 1598 cinco ediciones. 
estaba inspirada en romances llamados hoy fronterizos y moriscos, llenos de fantasías tergiversadoras de la realidad, e incorporados al texto como si fueran fidedignas fuentes históricas, romances por otra parte publicados ya en diversas antologías (Cancionero de romances, Silva de varios romances, Rosa de Romances de Timoneda, Flor de varios romances de Moncayo); de la misma forma, enseguida se advierten en la prosa del prolijo novelista numerosas anécdotas amorosas completamente literarias que dulcifican los últimos días de la Granada nazarí gracias a las trampas de la nostalgia. El ciclo de Reduán ${ }^{29}$ es una buena muestra de la pérdida de lastre militar y la amplificación amorosa atribuida a los héroes épicos del romancero fronterizo al desdibujarse en el morisco, en un paso cuya orientación había decidido en buena medida el Abencerraje, que apareció en un momento crucial, cuando empezaban a publicarse los primeros cancioneros de romances. Pérez de Hita no hizo más que seguir sus pasos, aunque entonces el proceso ya se hubiera cumplido y bien pudiera darse por cerrado; no obstante, incrementó hasta la extenuación la faceta sentimental en su novela (que se cifra ahora en la variedad de su casuística, y se adorna con justas y torneos); quizá eso explique en buena medida por qué la segunda parte de las Guerras Civiles de Granada (de hacia 1597, aunque la primera edición conservada es de 1619), de signo prácticamente opuesto, pasara sin pena ni gloria: no fue ni publicada ni menos traducida en Francia ${ }^{30}$. El lector ya podrá intuir cuál es la clave del éxito de la novela morisca y en qué sentido evoluciona

Además fue reimpresa en unas cuarenta ocasiones durante el siglo XVII, diez. en el siglo XVIII y cinco en el XIX. En Francia apareció una primera edición parisina en 1606; más tarde, en 1660, apareció otra en la misma ciudad y tres libreros se repartieron las ventas. En 1608, el librero parisiense Toussaincts du Bray ofreció una completa y exacta versión francesa. Más tarde, en 1683, apareció una traducción más infiel, a cargo de Mme de la Roche-Guilhem, que la acerca a la novela galante suprimiendo sin miramientos las largas descripciones de fiestas y combates, los detalles de los atuendos, los versos interpolados.

29. Excelentemente analizado por Luis Seco de Lucena (1963: 16-22).

30. Porque ahora Pérez de Hita explica hechos de los que fue espectador (e incluso actor): el levantamiento de los moriscos andaluces que durante tres años tuvieron en jaque el formidable poder militar de Felipe II. El resultado, por supuesto, está muy lejos de la idealización de la primera parte: en un momento dado, al verse obligado a dejar de lado los amores de Albexari y la bella Almanzora, comenta "y si no fuera porque esta historia es toda coscorrones y armas y batallas, tratáramos las ternezas destos dos amantes y sus extremados amores». En efecto, Pérez de Hita nos ofrece detalles de las batallas y también de la devastación humana que trajeron consigo: toda la miseria, la truculencia y el horror. El narrador se identifica a veces con las víctimas sin dejar de sentirse verdugo y culpable de pillajes y abusos. La obra, interesantísima desde el punto de vista histórico, quedó arrumbada por el gusto español de su tiempo, y completamente olvidada más allá de los Pirineos. 
para acrecentar su interés entre el público, no solo en España, sino también al otro lado de los Pirineos. Sobre todo si se tiene presente que tras treinta años de guerras civiles la novela sentimental española se lee en Francia como modelo de comportamiento refinado, pues ha cuajado en el centro de la reacción suscitada entre las damas "savantes", que bajo los auspicios de la devoción salesiana y su concepto del ocio laico, tiene por objeto civilizar a la «noblesse d'épée» ${ }^{31}$. En la conversación dedicada a la gloria (II, i) de Clélie, histoire romaine (1655), I Iermilie expone con claridad que ésta debería desvincularse de la hazaña militar: «Nous n'aurons plus grande part à la gloire selon Mutius, car les femmes ne vont pas à la guerre.. ${ }^{32}$ No importa cuán aguerridos sean los caballeros que surjan de la narrativa y los romances de tema granadino, pues el verdadero heroismo es para el ánimo femenino la elegancia masculina interior y exterior: por eso los torneos y fiestas -motivo preferente en las complejas intrigas de las Galanteries grenadines (1673) de Mme de Villedieu, tardía ya en su intento- irán siempre acompañados de consecuencias sentimentales, en un proceso de depuración de la parte épica que ganará cada vez más terreno en el gusto de la sociedad galante. Esta faceta emotiva es la que tras muchos avatares recibe un empujón definitivo en $L a$ Princesse, que aparece desnuda de cualquier disfraz exótico, ya sea antiguo, oriental o pastoril. Tan solo se acepta ahora una suave pátina del pasado reciente, con rutilantes alusiones al presente mundano.

\section{LA IDEALIZACIÓN DE JACQUES DE SAVOYE, DUC DE NEMOURS}

Brantôme era buen amigo de Nemours y en efecto admiraba su belleza, elegancia y gallardía. Reverenciaba también su éxito con las mujeres, que según le había comentado el propio Nemours se debía en buena medida a su atrevimiento (que desmerece al honneste homme de Faret y lo opone al prudente Prince de Clèves): "Je luy ay ouy raconter plusieurs fois de ses advantures d'amour; mais il disoit que la plus propre recepte pour jouyr de ses amours estoit la hardiesse.» ${ }^{33}$ Pero en el volumen de sus memorias dedicado a las vidas de los capitanes franceses se explaya ante todo en la parte militar de su trayectoria, la versión "oficial» de la vida del personaje: narra por ejemplo cómo tomó parte en los sitios de Lenz y de Metz y en la batalla

31. Vid. Marc Fumaroli (1994: 321-339).

32. (1655: 471). Vid. el capítulo tercero de Morlet-Chantalat (1994: 161-177).

33. Mérimée y Lacour (1895: 166). 
de Renty sin escatimar superlativos: «Il fit ses jeunes guerres en Piedmont, par deux à trois voyages qu'il fit, et en France aux sièges de Boulloigne, de Metz et bataille de Ranty et autres belles factions, en representation [con el sentido de "reputación"] d'un très-brave, vaillant et très-hardy prince.» Siempre fiel a los Guisa, llegó a ser coronel general de su caballería ligera. Vuelto a Francia tras una breve ausencia en la Saboya por motivos sobre los que volveremos, combatió contra los hugonotes con Guisa y Saint-André. Fue nombrado gobernador del Lionesado, Forez y Beaujolais, recuperó Vienne y sitió Lyon. Tomó parte en la batalla de Saint Denis, ayudó a Aumale a rechazar la invasión del duque de Deux-Ponts y fue a recibir a Henri III a Lyon, retirándose poco después a Annecy. Pero Brantôme no ha podido evitar la alusión a su ausencia, ańos antes, de Francia: es un punto oscuro que hubo de ensombrecer su brillante carrera antes de que estallara la primera guerra civil. Por primera vez su vida de seductor se había cruzado con su proyección pública al tropezar con «madamoyselle de Roan», de quien solo se dice aquí que fue la causa de ser delatado a la reina (Catalina de Medici) por una camarera llamada Denise "qui chantoit de las mieux" y "qu'il hayssoit fort mondict sieur de Nemours, a cause de madamoyselle de Roan». Pero sobre el contenido de la delación Brantôme pasa de puntillas: Nemours planeó llevarse a Henri de Orleáns (más tarde Henri III) a Lorena o a Saboya, para hacerle allí el jefe del partido. Le Laboureur explica, en cambio, por qué consistió una imprudencia y aporta detalles que cuestionan la categoría moral del personaje, llenando así la laguna del amigo del señor de Nemours en el apéndice a su edición de las memorias de Castelnau: resulta, apunta con ironía, que «ce Prince, le plus beau, le plus adroit, \& le plus accomply de son temps, mais qui n'estoit pas le plus fidéle en ses amitiez» decepcionó con engaños las esperanzas de contraer matrimonio de "Demoiselle Rohan", prima hermana del rey de Navarra: el matrimonio («contracté par paroles de present, \& consommé») se reveló por la necesidad de asegurar a un hijo que nació de esta unión. En un momento en que el rey de Navarra, que tomó parte en el affaire, era Lugarteniente general de la Corona y "estant encore redoutable par le party Huguenot», momento por otra parte en que a la reina le interesaba contemporizar con las dos religiones, no se sintió seguro, y en la duda de tener un problema en la corte o retirarse, optó por la segunda opción, no sin antes decidir llevarse al Príncipe d'Anjou y convertirlo en jefe del partido católico. Sin embargo, la empresa se desbarató, según Le Laboureur, porque la reina lo supo por el propio jeune enfant (y no por la camarera) que se lo contó todo a su madre. Interesa destacar aquí el papel poco encomiable (o con más precisión, cobarde) que siguió desempeñando 
Nemours según Le Laboureur: «le Duc s'enfuit en Savoye, \& laissa Lignerolles son Escuyer (...) en danger de sa teste pour avoir esté le principal Ministre de l'entreprise. ${ }^{34}$ Siguiendo su vocación de desvelar la verdad de cuanto sucedió, justifica el elogio de Brantôme por la amistad que ya le suponíamos: "mais nonobstant toutes ces preuves, le sieur de Brantome, comme fort affectionné qu'il estoit à ce Prince \& à la Maison de Guise, l'en veut justifier ses Memoires, ou il traite l'Eloge de ce Duc de Nemours». Aquí hemos copado con una cuestión ética, pero lo curioso es que aflora en la compulsa de los documentos históricos, porque la versión que Mme de La Fayette escoge explicitar del personaje es en principio la oficial y elogiosa de las Vies des grands capitaines. Sin embargo, su personaje es duramente castigado en su novela, pues entrega su corazón a la princesa (no deja de ser una prefiguración del don Juan vencido de Choderlos de Laclos) y aun así termina siendo rechazado ${ }^{35}$. Pero llegados a este punto quizá convenga recordar otros datos de las memorias de Brantôme que ayudan a colorear la trastienda del personaje: ya no se trata de la versión "oficial» del militar aventajado, de "la fleur de toute chevallerie», sino que de pronto, en la crónica mundana de la segunda parte del Recueil des dames (y no Dames galantes, como lo bautizaron sus editores), asoma el auténtico libertino que fue. Hay una facecia significativa en este sentido, en un escenario que supongo prostibulario, de la que participan, entre otros, no solo Jacques de Savoye, sino el propio Brantôme, junto al Vidamo de Chartres, otro seductor impenitente de la novela (pariente de la ficticia $M^{\text {lle }}$ de Chartres, después

34. Ofrece entonces como prueba las cartas del rey a su embajador, el sieur de Isle, del 3 de Noviembre de 1561 y la respuesta de dicho señor del 9 del mes siguiente, impresas en las memorias del Concilio de Trento de feu $M$. du Puy. En Chapitre neuviéme «Du Dessein du Duc de Nemours d'enlever le duc d'Orleans», Le Laboureur (1731: 774-775c). Henry Bourdeux narra en el capítulo "Les amants d'Annecy" (1922) la terrible e inacabable lucha en los tribunales y fuera de ellos de Françoise de Rohan contra el duque de Nemours, que llegó a aguar la celebración de sus esponsales con Anne d'Este.

35. Lástima que $\mathrm{H}$. Chamard y $\mathrm{G}$. Rudler no se detuvieran un poco más en distinguir entre las aportaciones sobre Nemours de Brantôme y de Le Laboureur y que no percibieran en la novela de la condesa cómo se proyectan las sombras del personaje real: «Malgré l'admiration qu'ils professent pour ses rares qualités de corps et d'esprit, Brantôme ni même Le Laboureur ne cachent rien de sa vilenie, et par eux Mme de La Fayette n'a pu manqucr dc connaîtrc à fond ce peu scrupuleux personnage. Elle a rejeté dans l'ombre tout ce qui eût atteint son honneur. Elle néglige les notes de Le Laboureur et suit son texte, où il présente en Nemours 'le véritable parangon de tous nos Paladins et de nos Preux du temps passé, le modèle de toutes les grâces et de toutes les vertus» en "La couleur historique», (1917-18: esp. 17-18). 


\section{BULLETIN HISPANIQUE}

Princesa de Clèves), cuya truculenta obscenidad me obliga a referirla en nota $^{36}$.

Es evidente que la condesa leyó y leyó muy bien las memorias de Brantôme, así como los addenda de Le Laboureur a las memorias de Castelnau, porque conocía todos los lados del personaje, un hombre en el que se daban la mano el cálculo del libertino y la capacidad de amar durante lustros a una dama casada, Vénus la Sainte de Ronsard, es posible que sin contacto físico alguno ${ }^{37}$. No resulta difícil imaginar cómo la condesa se inspiró en estas relaciones de la época para ir cincelando su creación. Me parece evidente, por ejemplo, que conocía otro fragmento acerca de Nemours que aparece en plena semblanza de François Lorraine, cuando se desvía la atención del caballero de Guisa para volver a fijarla en Jacques de Savoye: aunque eran buenos compañeros en la carrera militar, con la presentación de Brantôme no cuesta un gran esfuerzo concebirlos como rivales, sin volver a insistir aquí en que Nemours acabó casándose con la viuda de Lorraine, su largo tiempo amada Anne d'Este ${ }^{38}$. Se trata de la descripción de un juego de

36. En un excurso sobre distintas deformaciones posibles de los genitales femeninos, Brantôme se entretiene en la descripción de los labios menores desorbitadamente alargados que ha observado en ciertas mujeres, y recuerda entonces como una gracia cuya narración provocó grandes carcajadas al rey, la siguiente anécdota: «...une fois, estans de bons compagnons à la court ensemble, comme M. de. Nemours, M. le vidame de Chartres, M. le comre de I.a Rochefoucault, MM. de Montpezac, Givry, Genlis et autres, ne sçachans que faire, allerent voir pisser les filles un jour, cela s'entend cachez en bas et elles en haut. Il y en eut une qui pissa contre terre: je ne la nomme point; et d'autant que le plancher estoit de tables, elle avoit ses lendilles si grandes qu'elles passerent par la fente des tables si avant qu'elle en monstra la longueur d'un doigt; si que M. de Randan, par cas, ayant un baston qu'il avoit pris à un laquais, où il y avoit un fiçon, en perça si dextrament ses landilles, et les cousit si bien contre la table, que la fille, sentant la picqueure, tout à coup s'esleva si fort qu'elle les escerta toutes, et de deux parts qu'il y en avoit en fit quatre; et lesdites lendilles en demeurerent decoupées en forme de barbe d'escrevices; dont pourtant la fille s'en trouva tres-mal, et la maistresse en fut fort en colere. M. de Randan et la compagnie [entre los que se encuentra M. de Nemours] en firent le conte au roy Henry, qui estoit bon compagnon, qui en rit pour sa part son saoul, et en appaisa le tout envers la reine, sans rien en deguiser.», Brantôme (1962: 254-256).

37. Este gran amor por Anne d'Este, lastrado por la culpa del compromiso no cumplido con Françoise de Rohan, queda insinuado también en Les vies des grands capitaines: «Pour en aymer trop une et luy estre fort fidelle, il ne voulut aymer l'autre, qui pourtant l'aymoit tousjours" (1895: 166).

38. Valentin Poizat (1920) defiende, rotunda, la identificación de esta antigua enamorada de Nemours, que al enviudar casó con él, con la protagonista de nuestra novela. No sería de extrañar que la condesa se inspirara parcialmente en ella, pero no hay que confundir la distorsión que propone la ficción con respecto a los elementos tomados de la realidad, con esta última; Henry Bourdeux se encarga de desautorizar las conclusiones demasiado ingenuas 
sortija en que ambos caballeros participaron disfrazados a la bufonesca de gitana el primero y de «bourgeoise de ville» el segundo, y éste llevaba además «à sa ceinture une grande bourse de ménage avec un grand clavier de clefs, ou pour le moins il y avoit plus de cent clefs pendants avec la grosse chaisne d'argent» y de esta guisa hizo dar unos portentosos saltos a su caballo, en una actuación tan brillante -de milagrosa la tilda Brantôme-con el ruido de fondo de las llaves entrechocando entre sí, que llenó de admiración a la sala, y especialmente a "une Dame qu'il servoit $\&$ aimoit fort, aussi elle luy ${ }^{39}$. No hay que ser muy imaginativo para barruntar que las llaves podían ser una alusión simbólica a esa dama que le observaba, cuyo apellido pretendía evocar. Por otra parte, la renuncia a viajar a Inglaterra para galantear a la reina Virgen también está tomada directamente de la segunda parte del Recueil, donde se insinúa que la súbita pérdida del interés por parte del aristócrata francés fue a causa de unos amores; síntoma probable de la inconstancia del personaje, y no obstante en la novela, sin anular esta interpretación, es vivido por la protagonista como prueba secreta del carácter insólito del amor que le profesa Nemours.

Para entender cómo procedió la inspiración de la novelista paseando su mirada por las crónicas del XVI, conviene comprender un poco mejor al célebre memorialista Brantôme -su principal fuente en la construcción del personaje de Nemours- y las contradicciones que hay en su obra. Pierre de Bourdeilles (1540-1614) pasó su infancia en la corte de Marguerite de Navarre hasta 1549 , fecha de su muerte, donde su madre, viuda, fue dame du corps de la reina, mientras su abuela era dame d'honneur. Cuando terminó sus estudios en París y Poitiers no tardó en heredar la abadía de Brantôme de la que tomó el nombre, aunque se dedicara a la carrera militar y a viajar por toda Europa para codearse con la mayoría de los personajes que han desempeñado un papel de relevancia en el siglo XVI. Conoció también Espańa, pues al entrar en 1564 al servicio de la casa del duque de Orléans, que después sería Henri III, en calidad de uno de sus gentilhombres y con 600 libras de gajes, el cargo no le dio ninguna ocupación, y así se enroló en una expedición espańola contra los moros. Una armada de diez mil hombres bajo las órdenes de García de Toledo atacó en 1564 el Peñón de

de Poizat en «Les amants d'Annecy», vid. supra n. 34.

39. Me pregunto si en esta ocasión no le estaría echando los tejos a Catherine de Clèves, esposada en 1570 con el hermano de François, Henri de Guise. En cualquier caso, no importa quien fuere la dama en cuestión. Lo interesante es que quizá de este pasaje surgiera la idea de dar el nombre de Clèves a la enamorada ficticia de Nemours. Pero todo son conjeturas. 
Vélez; tomado el peñón (donde según Brantôme solo les aguardaban sesenta turcos que huyeron a los primeros cańonazos), desembarcó en Lisboa, llegó hasta Madrid, donde al parecer fue muy bien recibido por la reina Isabel, encantada de que un compatriota le trajera noticias frescas de la corte francesa. Años más tarde, en plena decadencia personal, defraudado por el rey de Francia y descontento con los Guisa, volvió a sentirse atraído por la corte espańola ${ }^{40}$. Estos viajes explican su conocimiento del español (lucido sin remilgos aunque diste mucho de ser perfecto), presente en los dichos con que le gusta menudear su obra, sin olvidar las Rodomontades ${ }^{41}$. Pero tuvo un accidente a caballo en 1584 que le rompió los riñones y obligó a guardar cama cuatro años, durante los que su cuñada, la viuda de su hermano André, le cuidó con esmero. Apartado en su abadía, entretuvo su obligado descanso dictando sus conocidas y jugosísimas memorias.

Hay ciertas contradicciones en ellas que pueden ser muy reveladoras de las distintas caras del personaje histórico que nos ocupa (me refiero a Jacques de Savoye): Prosper Mérimée lo ha notado con sagacidad en su edición de la obra de Brantôme: la expedición de la Armada Invencible, por ejemplo, se describe con muchos miramientos en torno a la figura de Felipe II, en la parte que se le consagra, mientras que esta expedición provee en las Rodomontades de detalles ofensivos para el mismo monarca que es presentado ahora como un loco furioso ${ }^{42}$. Saint-Marc-Girardin, así como otros después de él, añade Mérimée, han repetido que Brantôme era tan indiferente al bien como al mal. Esto no es cierto del todo, afirma con convicción. El mal le seducía más. "Ainsi la vertu des femmes l'agace visiblement; il va jusqu’à prétendre qu'une femme mariée se livrant à quatre amis est plus honorable qu'une veuve deux fois remariée. Il déprécie l'héroïne préférant la mort au déshonneur. (...) Pas un mot d'estime pour l'hérö̈sme inspiré de Jeanne d'Arc, pas une parole de regret pour son martyre! Non! Elle a été brûlée; eh bien, tant pis pour elle! Cela servira d'enseignement aux filles qui font les garçonnières. En matière semblable, du reste, ne demandez à Branthôme rien de chevaleresque, bien qu'il invoque à tout propos les preux du vieux temps. (...) Nous croyons en avoir assez dit pour montrer que l'indifférence de Branthôme pour le bien confine au mépris. En revanche, son indifférence

40. Para la biografía de Brantôme me baso fundamentalmente en la «Introduction a la table alphabétique générale» de la edición de Mérimée y Lacour, t. 13, (1895). Vid. también el amplio estudio de Ludovic Lalanne (1896).

41. Sobre dicho género, vid. el resumen que ofrece A. Cioranescu (1983: 108-113). Vid también Joaquín López Barrera (1923: 3-28).

42. Mérimée y Lacour, t. 13 (1895: 105). 
pour le mal paraît souvent nuancée d'une certaine admiration. (...) Du reste, un meurtre ne compte pas pour lui, bien qu'il n'ait jamais fait de mal à personne. ${ }^{43}$ Estas consideraciones ayudan a entender mejor el tratamiento que por ejemplo recibe Catalina de Medici, elogioso en la primera parte del Recueil, lleno de insinuaciones (sin dar el nombre) sobre sus maldades y su degenerada sexualidad en la segunda. $\mathrm{Y}$ he aquí, creo entender también, la clave de su admiración por Nemours y su insensibilidad hacia los puntos oscurus de su personalidad, sobre todo porque su infidelidad con las mujeres no le atañía como amigo y compañero de juergas nocturnas; en cambio, esos destellos de misoginia que despide su comportamiento, consignados por la pluma indiferente del abad, hubieron de causar profunda impresión un siglo más tarde en la condesa de La Fayette. Vista así, quizá su obra pudiera interpretarse como el plato de la venganza femenina, servido un siglo más tarde deliciosamente aderezado en su bella y calculada prosa ${ }^{44}$.

Si analizamos la obra con más detalle, puede que estemos en condiciones de espigar algún momento en que el "atrevimiento" de Nemours se adentra en el terreno literario y proyecta sombras sobre su imagen, para provocar un devastador efecto dominó en el interior de la princesa con largos y torturados razonamientos tan impecables como contradictorios. Todos los pasos en falso de Nemours tienen su reflejo, además, en la segunda parte del Recueil des Dames, que consignaré en nota. El silencio con que el duque sobrelleva su amor, cuya destinataria queda oculta a todos menos a ella misma, y que es uno de sus atractivos más irresistibles en medio del comadreo de la corte, se rompe de pronto cuando escucha, agazapado en el jardín de Coulommiers, la insólita confesión de la princesa a su esposo. La euforia de verse correspondido le hace olvidar su contención y le falta tiempo para contar en tercera persona el caso que acaba de presenciar al Vidamo de Chartres, compañero de fatigas noctámbulas en las crónicas de su tiempo ${ }^{45}$. Como

43. T. 13 (1895: 105-106).

44. No puedo adentrarme ahora en los vericuetos de La Carte du Tendre interpolada en Clélie (1655-1660) de Mlle de Scudéry ni en las influencias jansenistas de su autora, perteneciente al círculo de Mme de Sablé y asidua de la condesa du Plessis en el hôtel Nevers, que atañen exclusivamente al contexto francés, ya estudiado. Vid., por ejemplo, el reciente libro de Benedetta Craveri inspirado en buena medida en las memorias de Mme de Motteville, fiel dama de compańía de la reina Ana de Austria (2003), esp. el capítulo dedicado a "La marqucsa de Sablć: cl salón en el convento». Solo recordaré aquí una sugerencia de Ana María Holzbacher, que interpreta ese rechazo del galán irresistible como una posible venganza personal de la autora, por hipotéticos motivos biográficos: su escasa belleza, algún enamoramiento de la adolescencia frustrado...(1987: 63-66).

45. Esa indiscreción tiene un precedente en Guenelic, cuyas fanfarronadas también 


\section{BULLETIN HISPANIQUE}

veloz bumerán, la historia llegará a oídos de la princesa, tras pasar por boca de la amante clandestina del vidamo y de ella a la delfina. Sin importarle recurrir al engaño ${ }^{46}$, en cuanto tenga ocasión de hablar del asunto con su enamorada, Nemours intentará colgar la indiscreción al príncipe de Clèves.

Otro momento extraordinariamente brillante de la novela tiene lugar cuando llega a manos de la delfina una carta amorosa dirigida a un caballero que tuvo la mala fortuna de extraviarla en el jeu de paume: las sospechas recaen enseguida en el duque de Nemours, precedido siempre en sus actos por su fama de seductor, y como si a él estuviera dirigida, la joven protagonista la lee paralizada por el estupor de los celos. No me puedo demorar en la descripción de todas las posibilidades combinatorias que la autora explota de este recurso literario (la interpolación de una epístola en el seno de la ficción sentimental), tan solo mencionaré que proporciona uno de los momentos más emocionantes, pues permite al lector descubrir junto a la -hasta entonces- contenida princesa la violencia de su confusión y de sus celos; ofrece también el más sofisticado pretexto para que Nemours pueda entrar en sus aposentos con la aquiescencia del señor de Clèves y pase largo rato de intimidad con ella en la redacción de la falsa carta destinada a salvar la reputación del vidamo.

La interpolación de mazos de cartas es un recurso novelístico heredado de la novela epistolar, de larga prosapia europea, que Diego de San Pedro contribuyó en buena medida a poner en boga, recurso del que también echó mano Montemayor en la Diana. Pero en la novela de Montemayor la deuda del género epistolar no solo se puso de manifiesto en la intercalación de alguna que otra carta, sino en la creación de todo un lenguaje para la expresión del mundo interior de sus personajes (última derivación literaria, mediatizada por la influencia de Guevara, del ars dictaminis) que el narrador disecciona parsimoniosamente desde la tercera persona sin renunciar casi nunca a la omnisciencia: no por otra razón contituye la Diana un precedente insoslayable de la novela de análisis ${ }^{47}$.

\footnotetext{
llegarán a oídos del esposo de la princesa. La actitud de Nemours, por otra parte, parece inspirada en algún comentario (vid., sin ir más lejos, más arriba, nota 36) como el que sigue de Brantôme, teñido de admiración: «...M. de Nemours, le parangon de toute chevallerie: car, si jamais prince, seigneur ou gentilhomme a esté heureux en amours, ça esté celuy-là. Il ne prenoit pas plaisir à les cacher à ses plus privez amis; si est-ce qu’à plusieurs il les a tenues si secretes qu'on les jugenit que malaisement. Certes, pour les dames mariées, la descouverte en est fort dangerouse; mais, pour les filles et veuvfes qui sont à marier, n'importe: car la couleur et pretexte d'un mariage futur couvre tout.», Brantôme (1962: 473).

46. Recuérdese sin ir más lejos la historia de Demoiselle Rohan.

47. Versini sabe ver también la tradición epistolar en «les soliloques d'une Mme de La Fayette
} 
La economía de motivos y la desnudez descriptiva (en contraste con la novela heroica francesa ajustada o no al modelo narrativo de Ginés Pérez de Hita) forman parte, en cambio, de la búsqueda de brevedad y verosimilitud ${ }^{48}$ que Huet ponderaba en su Traité de l'origine des romans de 1670, añadido a la primera edición de Zaïde como prefacio: moderación responsable de haber devuelto la novela "à son vrai ton" ya apreciable en la Princesse de Montpensier (1662) y de la compleja y densa motivación narrativa con que ahora se elige insertar el texto de una sola carta. Pero el gusto por la brevedad no disminuirá por esta razón la atracción francesa por la Diana, pues Mme de Saintonge se encargará de adaptarla a los nuevos tiempos en una traducción infiel, que como las Guerras civiles de Mme de la Roche-Guilhem (1683), cercenará cuantos tropiezos resten fluidez a la narración. En este nuevo contexto literario, que no por distinto deja de ser heredero del anterior, es donde hay que inscribir la gran tensión narrativa que Mme de La Fayette sabe desplegar a partir de la intercalación de una única misiva amorosa. La carta extraviada, de enigmáticos remitente y destinatario ${ }^{49}$, desata una tormenta emocional desconocida para la jovencísima e inexperta protagonista (casi tan tierna como Fiammetta y Hélisenne). Le sirve, en fin, de experiencia sustitutiva: al leerla, la analiza con sutileza detectivesca, y días más tarde, disecciona en frío los sentimientos que en ella despertó como si formaran parte también de una lectura literaria. Al conseguir objetivarse, se sorprende entonces «de n'avoir point encore pensé combien il était peu vraisemblable qu'un homme comme M. de Nemours, qui avait toujours fait paraître tant de légèreté parmi les femmes, fût capable d'un attachement sincère et durable "s0. Así, la idealización novelesca de Nemours, en que consiste el enamoramiento de

qui, sans faire servir la lettre autrement que par exception, lègue paradoxalement au genre épistolaire un instrument progressivement assumé.» (1979: 49).

48. Es de notar, sin embargo, las duras críticas que Bussy-Rabutin despliega en su carta de contestación a Mme de Sévigné (del 26 de Junio de 1678) sobre la falta de verosimilitud de las escenas clave de La Princesse, y cómo a su querida prima, que tan amiga se considera de Mme de La Fayette, le falta tiempo para ponerse de acuerdo con él (carta del 27 de Julio), (1974: 617 y ss.).

49. Es éste, por otra parte, un episodio novelesco, basado en el histórico amor odio de Catalina de Medici hacia el vidamo de Chartres, que de nuevo trae consigo connotaciones de un acontecimiento contemporáneo a la condesa, la carta que se perdió durante una recepción de Madame de Montbazon, y se sospechó enseguida que había caído del bolsillo de Coligny, que por lo que se cuchicheaba, estaba enamorado de Madame de Longueville: el caso empezó como un juego de adivinanzas palaciego y acabó degenerando en un asunto de estado en el que Ana de Austria se vio obligada a intervenir, Craveri (2003 : 100-105).

50. Princesse (1939: 330). 


\section{BULLETIN HISPANIQUE}

la princesa, queda oscurecida por las sombras del personaje histórico, que se filtran a través de recursos estrictamente literarios en la obra y justifican el terror que por momentos invade a su protagonista. Ese pánico da verosimilitud psicológica a la variedad de argumentos que se da a sí misma para el rechazo y también justifica el autoanálisis de sus reacciones como si formaran parte de una obra literaria que permitiera «reescribir» su desenlace -recordemos la función de advertencias que tienen las historias secundarias ${ }^{51}$. En definitiva, su amor vivido como una novela ${ }^{52}$ le ayuda a adueñarse de su destino. Solo un subterfugio como sustituir la experiencia vital por otra literaria -en una nueva manifestación oblicua de lo sentimental- podría oponer la distancia necesaria para alejarse de la más violenta de las pasiones.

\section{LA CARCEL DE AMOR Y LA DIANA COMO MODELOS DE NARRACIÓN EMOCIONAL}

En cuanto la autora termina el lento travelling por las figuras de los personajes históricos con que da comienzo la novela, la fama de la belleza de la protagonista irrumpe en la corte, precediendo su nombre. La descubre el señor de Clèves en casa de un joyero italiano. Sin apenas describirla, Mme de La Fayette consigue dotarla de carácter superlativo gracias al profundísimo

51. El relato secundario es otra posible aportación de la Diana, imitada en este sentido por Cervantes a partir de un cierto punto de la primera parte del Quijote, con tanta asiduidad, que le obliga al traslado precipitado de los capítulos consagrados a la historia de Marcela y Grisóstomo para equilibrar las ramificaciones de la historia principal. E.C. Riley considera que el relato intercalado, junto a la recitación o canto de poemas, contribuyó notablemente al desarrollo de la «auto-conciencia literaria» en la novela pastoril. Considera inherente a este tipo de novelas cierta actitud crítica que hubo de inspirar a Cervantes en muchos aspectos y coadyuvó por tanto al inmediato desarrollo de la novela moderna (1971: 61-62). Creo que en la Princesse podemos observar otra derivación hacia la novela universal del mismo recurso literario. Acerca de los vaivenes del gusto por el relato intercalado en el XVII francés, vid. Yllera (1992: 109-117), y acerca de su fortuna en el XVIII, Cots (1992: 131-140).

52. Nótese, por ejemplo, la reivindicación de la originalidad de la propia confesión al acusar equivocadamente al Príncipe de Clèves de su divulgación, pues a nadie más se le podría haber ocurrido: "Ah! monsieur, reprit-elle. il n'y a pas dans le monde une autre aventure pareille à la mienne; il n'y a point une autre femme capable de la même chose. Le hasard ne peut l'avoir fait inventer; on ne l'a jamais imaginée et cette pensée n'est jamais tombée dans un autre esprit que le mien...", Princesse (1939: 349). Sin embargo, Valincour, en sus Lettres à la marquise sur le sujet de La Princesse de Clèves, señalaba que esa escena de la confesión, cuya novedad reivindicaba ardorosamente su protagonista, se había tomado de Les Désordres de l'amour de Mme de Villedieu, aparecida dos ańos antes. El problema es que es muy posible que la Princesse o un esbozo de la misma, circulara manuscrita desde principios de los ańos setenta, vid. supra n. 8. 
efecto que surte en el señor de Clèves: la admiración, la sorpresa, el asombro ya no abandonan el interior de este caballero, tan impresionado por su hermosura. Del preámbulo de la novela, con los hieráticos miembros de la corte dispuestos en torno a la figura del rey, se pasa a este primer desvío de la perspectiva. La aparición de la señorita de Chartres descrita a través del punto de vista de un joven noqueado por su belleza pone en movimiento los sentimientos de rivalidad cortesana -orquestados en última instancia por Diane de Poitiers- y empieza la acción de la novela. Este detalle escurridizo resulta axial en la configuración de la estrategia narrativa de esta obra magistral. Mme de La Fayette no describe las escenas en su exterior (de hecho escasean las acotaciones, la novela es de una desnudez de decorados casi total), sino que combina de forma constante la omnisciencia narrativa con el punto de vista de uno de los caracteres y escoge siempre el personaje al que los acontecimientos que se están narrando golpean interiormente con especial fuerza.

Antes de saber qué sentimientos descubre en su fuero interno la protagonista al conocer al gran amor de su vida, el narrador deriva su atención con sutileza hacia el efecto que produce en la figura de un tercero la visión de ambos juntos al ser presentados en el baile. La autora refiere de esta manera el primer encuentro de los enamorados en la boda de Monsieur de Lorraine: el señor de Nemours llegó tarde al Louvre, cuando el baile ya hacía un buen rato que había dado comienzo, y se aproximó a la princesa saltando ágilmente por encima de unos asientos ${ }^{53}$. Quedó tan sorprendido de su belleza, que cuando estuvo a su lado y ella le hizo la reverencia, no pudo por menos de mostrarle su admiración. Cuando empezaron a bailar, se levantó en la sala un murmullo de alabanzas. Bailaron, formando muy buena pareja a ojos de todos, y al término del baile la delfina los presentó a petición de Nemours, aunque él ya la había reconocido:

\footnotetext{
-Pour moi, madame, dit M. de Nemours, je n'ai pas d'incertitude; mais comme Mme de Clèves n'a pas les mêmes raisons pour deviner qui je suis que celles que j'ai pour la reconnaître, je voudrais bien que Votre Majesté eût la bonté de lui apprendre mon nom.

-Je crois, dit Mme la dauphine, qu'elle le sait aussi bien que vous savez le sien.
}

53. El detalle está probablemente inspirado en la aparición de Montmorency en la vida de una jovencísima Madame de Sablé, quien se quedó prendada de tan apuesto joven al verle aparecer dando volteretas por la ventana Craveri (2003: 137). Sobre esta misma escena y su preparación en el tiempo, por medio de informaciones indirectas, vid. Rousset (1984: 104108). 


\section{BULLETIN HISPANIQUE}

-Je vous assure, madame, reprit Mme de Clèves, qui paraissait un peu embarrassée, que je ne devine pas si bien que vous pensez.

-Vous devinez fort bien, répondit Mme la dauphine; et il y a même quelque chose d'obligeant pour $M$. de Nemours à ne vouloir pas avouer que vous le connaissez sans l'avoir jamais vu.

La reine les interrompit pour faire continuer le bal; M. de Nemours prit la reine dauphine. Cette princesse était d'une parfaite beauté et avait paru telle aux yeux de M. de Nemours avant qu'il allât en Flandre; mais, de tout le soir, il ne put admirer que Mme de Clèves.

Le chevalier de Guise, qui l'adorait toujours, était à ses pieds, et ce qui se venait de passer lui avait donné une douleur sensible. Il [le] prit comme un présage que la fortune destinait $\mathrm{M}$. de Nemours à être amoureux de Mme de Clèves; et, soit qu'en effet il ềt paru quelque trouble sur son visage, ou que la jalousie fit voir au chevalier de Guise au delà de la vérité, il crut quelle avait été touchée de la vue de ce prince, et il ne put s'empêcher de lui dire que M. de Nemours était bien heureux de commencer à être connu d'elle par une aventure qui avait quelque chose de galant et d'extrordinaire ${ }^{54}$.

Esta escena evoca otra de la Cárcel de amor (1492) de Diego de San Pedro que en su esencia es muy parecida; no olvidemos aquí que el público francés había sido muy aficionado a la novelita castellana, de la que se conservan ocho reediciones de su primera traducción en 1525, además de las catorce reediciones de la versión de 1552 en formato bilingüe. Todavía seguía despertando interés en pleno siglo XVII, del que quedan como testimonio una edición, también bilingüe, de 1616, y otra de fechas más próximas a la Princesse, de $1650^{55}$.

Cuando Leriano se recupera de su postración amorosa por no haber obtenido respuesta de Laureola a sus cartas, acude a la corte y allí es presentado por vez primera a su amada en presencia del Auctor (que coincide con la voz del narrador). La escena, observada de cerca por Persio -el celoso pretendiente de la princesa- que percibe con evidencia la turbación de ambos, será el desencadenante de nuevos impedimentos que terminarán

54. Princesse (1939: 262-263). La cursiva es mía.

55. Vid. Cioranescu (1977). A diferencia de Scarron o Boisrobert, Mme de La Fayette no se inspira en María de Zayas o en Juan Pérez de Moltalbán, por poner dos ejemplos de novelistas espańoles del XVII, con sus truculentas pasiones; la dignidad y contención en que se mueven los enamorados de la condesa está más en deuda con Segrais; los posibles ecos de lecturas españolas le llegan de forma más indirecta (a través de reelaboraciones literarias o traducciones) y a la manera de sutil recuerdo. Creo que Cioranescu se refiere a un contexto aparentemente más inmediato cuando afirma: «S'il s'agit du tumulte intérieur, l'influence de la fiction littéraire espagnole semble s'évanouir. La Princesse de Clèves, qui est un roman historique et psychologique à la fois, apparaît libre de la contamination espagnole, que l'on décèle cependant dans les autres romans de son auteur.» (1983: 471). 
revelándose insalvables para la pareja. Aunque la princesa Laureola trata de ocultar su desconcierto, Persio advierte enseguida su apuro, lince penetrador de lo que piensa:

Cuando besó las manos a Laureola pasaron cosas mucho de notar, en especial para mí, que sabía lo que entre ellos estaba; al uno le sobraba turbación, al otro le faltaba color; ni él sabía qué decir ni ella qué responder, que tanta fuerza tienen las pasiones enamoradas, que siempre traen el seso y discreción debajo de su bandera, lo que allí vi por clara experiencia.

$Y$ puesto que de las mudanzas dellos ninguno toviese noticia por la poca sospecha que de su pendencia había, Persio, hijo del señor de Gavia, miró en ellas trayendo el mismo pensamiento que Leriano traía; y como las sospechas celosas escudriñan las cosas secretas, tanto miró de allí adelante las hablas y señales dél que dio crédito a lo que sospechaba, y no solamente dio fe a lo que veía, que no era nada, mas a lo que imaginaba que era todo...56

Pero esta focalización, que asocia el primer encuentro de los enamorados en presencia de toda la corte a su repercusión íntima, emocional, en un tercero, no se ciñe en la novela francesa al fragmento de evidentes similitudes con la escena de Diego de San Pedro, sino que la condesa hace extensivo el recurso a la totalidad de su obra. Así, la Princesse de Clèves multiplica sus dimensiones afectivas pues reparte la narración, en búsqueda del contrapunto, en las distintas perspectivas con que se observan y sienten unos mismos acontecimientos, hechos que a lo mejor son tan sutiles y poco exteriorizados que resultan invisibles para quien se siente indiferente a ellos. Este zigzagueo de la trama a través de las distintas emociones se desarrolla hasta sus últimas consecuencias ahora, casi dos siglos después de la aparición de la Cárcel de amor, y está llevado con cálculo milimétrico en medio de una maraña complejísima de relaciones, muy propias por otra parte del ambiente áulico. Al tiempo que la novela gana en complejidad narrativa y densidad sentimental y psicológica, resulta una técnica narrativa eficacísima, pues va retrasando el resultado de todos estos movimientos del ánimo y sosteniendo la atención del lector, mientras satisface con cuentagotas su curiosidad acerca de cuanto ocurre en las distintas sensibilidades: la fragilidad del amor -clandestino se siente con más fuerza y no menos el peligro que le acecha.

Hay otra forma oblicua de narrar en la Princesse de Clèves cuya deuda parece también en última instancia española. Hace ya más de diez años, observé que el texto del Abencerraje incluido en la Diana, de acuerdo con el resto de la novela, que hereda y amplifica en su prosa redundante

56. San Pedro (1985: 113). 
y perifrástica la tendencia poética petrarquista y garcilasiana al fino análisis de los sentimientos, estaba cuajado de amplificaciones acerca de la descripción externa y sobre todo interna de los caracteres. $Y$ en este sentido, el estilo empleado, cargado de negaciones que rehuían la aseveración directa y buscaban dar un rodeo a través del circunloquio y la preterición, el estilo cargado de un ritmo irregular, esencialmente rítmico, era del todo imprescindible. No solo eso, se hizo evidente algo que por obvio que parezca no había sido notado: la inmensa mayoría de las frases de la novela de Montemayor (y del Abencerraje inserto en ella) son negativas. O sea que la primera novela psicológica que se escribe no ya solo en España sino en Europa, heredera de la prosa de fuerte impronta epistolar de San Pedro, evita el estilo asertivo y busca de forma obsesiva en la atenuación y la perífrasis la expresión de los sentimientos de la forma más estilizada y menos directa posible. Quiere esto decir que en cuanto los sentimientos amorosos pasan a protagonizar la novela su lenguaje apropiado es la negación de los mismos. No deja de ser una paradoja interesante. Es muy difícil que Francia hubiera podido desatender ese precedente retórico de la novela española, que le llegó a través de las numerosas traducciones de la Cárcel de amor y de la novela de Montemayor (ocho distintas en poco más de un siglo, que incluyen ese Abencerraje sentimentalizado y lo popularizan), legado que también le alcanzó a través, por supuesto, del cedazo que suposo l'Astrée, en cuya lectura se formaron las primeras preciosas. Y una prueba más de que ese precedente está presente después de muchos avatares, y despojado del ropaje musulmán o pastoril, en la novela galante de la condesa, es la preferencia que en ella puede observarse por la negación, que tanto menudeaba en la obra de Honoré d'Urfé. En efecto, de manera semejante a las buscadas redundancias de Montemayor ${ }^{57}$, abundan en La Princesse la preterición, la lítote, los superlativos absolutos e incluso la hipérbole ${ }^{58}$. Sabemos por sus cartas, que el estilo de Madame de La Fayette podía ser vivaz, escueto y pragmático. Pero en su novela sentimental, cambiaba de registro, y observados con lupa, parece como si sus recursos fueran en exceso reiterativos (como por ejemplo en la repetición descuidada de la conjunción «que»), lo que no le resta ductilidad, sino todo lo contrario, le da al discurso un dejo négligé, conversacional, muy acorde con el espíritu de su tiempo ${ }^{59}$. Tras esas redundancias hay en efecto

57. Sus primeros traductores no respecaban esta buscada limitación, rompiéndola en la pertinaz búsqueda de la variatio.

58. Vid. Holzbacher (1987: 69-72).

59. Vid. Marc Fumaroli, «Lart de la conversation, ou Forum du royaume», (1994: 283320 ). 
una finísima capacidad de penetrar en el interior de los personajes y darles vida, siguiendo las complejidades y altibajos de su sentir: la condesa hace gala de una gran flexibilidad en el manejo del diálogo, en la alternancia del estilo indirecto e indirecto libre, que transcribe los pensamientos; incluso a veces, como explica muy bien Ana María Holzbacher, el estilo directo de la narración y de los diálogos se da también en los soliloquios, "cuando el personaje se deja llevar por la vehemencia, e irrumpe la palabra, quizás en voz alta " ${ }^{60}$. Sc percibe también un gran sentido del ritmo, como a su vez sucede en la misma Diana. Pero en la Princesse el recurso de la atenuación, como el de la carta ( $y$ en cierto sentido también del relato intercalado y las cuestiones de amor), no es indiscriminado, sino que se emplea solo en el momento preciso $-y$ entonces se incrementa su sofisticación, siempre en pos de la originalidad. Por escoger un ejemplo al azar: hay tanta lítote en la explicación que Mme de Chartres se da a sí misma para entregar la mano de su hija a un hombre al que sabe que no ama, y vuelve a encadenarse tanta negación en el único intercambio verbal transcrito entre Mademoiselle de Chartres y el príncipe de Clèves, que la boda no tarda en celebrarse, con todas sus funestas consecuencias ${ }^{61}$.

60. Vid. el epígrafe "Estilo y técnica narrativa» de Holzbacher (1987: 69-72).

61. Funestas para M. de Clèves, dulces para su señora, pues Mme de La Fayette solo permite sobrevivir al amor de sus protagonistas en el permanente sorteo de obstáculos. Cuando la traba del matrimonio desaparece, el amor entra en agonía y fallece. La condesa ha tenido el acierto de transformar el ejemplo paradigmático de Leriano y su inútil sacrificio en un personaje secundario pero axial: convertido en el esposo desdeñado y depresivo de $M$. de Clèves, su muerte por amor no puede ser más ajena a la pasión de los protagonistas, pero tiene la singular virtud de romper el sistema triangular de narrar definitorio de la Princesse. Por eso Nemours deja de progresar en el interior de su amada. Porque esa muerte del tercero vulnerado desencadena el fin del arte de narrar y del amor mismo. 


\section{BULLETIN HISPANIQUE}

\section{Bibliografía}

Boccaccio, G., Elegia di Madonna Fiammetta, Opere minori in volgare, v. 3, Milano, Rizzoli Editore, 1971.

Bourdeux, H., Amours du temps passé, Paris, Librairie Plon, 1922.

Brantôme, Les vies des grands capitaines du siècle dernier, seconde partie (suite), Les vies des grands capitaines françois du siècle dernier, ed. de Mérimée, P. y Lacour, L., t. 5, Paris, Librairie Plon, 1895; Graus Reprint, Nedeln-Liechtenstein, 1977.

- Euvres complètes de Pierre de Bourdeilles, abbé et seigneur de Brantôme, Paris, Librairie Plon, t. 13, 1895; Graus Reprint, Nedeln-Liechtenstein, 1977.

- Les dames galantes, ed. Pascal Pia, Le Livre de Poche Librairie Générale Française, 1962.

Brownlee, M. S., The Severed Word. Ovid's Heroides and the Novela Sentimental, Princeton, Princeton University Press, 1990.

Carrasco URgortr, S., El moro de Granada, (1956) reed. facsimilar de la Universidad de Granada, 1989.

Castelnau, M., Les Memoires de Messire Michel de Castelnau seigneur de Mauvissiere. Illustrez et augmentez de plusieurs commentaires of Manuscrits, tant Lettres, Instructions, Traitez, qu'autres pieces secretes \& originales, servans à donner la verite de l'histoire des Regnes de François II, Charles IX \& Henri III \& la Regence du Gouvernement de Catherine de Medicis, avec les eloges des Rois, Reines, Princes \& autres Personnes illustres de l'une \& de l'autre Religion... par J. Le Laboureur, tomo I, Bruxelles, 1731, (primera edición de 1659).

Cazenave, J., "Le roman hispano-mauresque en France», Revue de Littérature Comparée, V (1925), 594-640.

Cioranescu, A., Bibliografía francoespañola (1600-1715), Madrid, Anejos del Boletín de la Real Academia Española, Anejo 36, 1977.

- Le Masque et le Visage, Genève, Droz, 1983.

Cordelier, J., "Le refus de la Princesse», en XVII siècle. Revue publiée par la Société d'Étude du XVII' siècle, 108 (1975), 43-57.

Cots, M., "Funciones del relato intercalado en algunas novelas francesas del siglo XVIII», El relato intercalado, Madrid, Fundación Juan March, Sociedad Española de Literatura General y Comparada, 1992, 131-140.

Couture, R.A., L'imputabilité morale des premiers mouvements de sensualité de Saint Thomas aux salmanticenses, Roma, Presses de L'Université Grégorienne, 1962.

Crenne, Hélisenne (de), Les angoysses douloreuses qui procedent d'amours, edición y prólogo de Loviot y de M. V.-L. Saulnier, Paris, Les belles Lettres, 1968.

Chamard, A.H, y Rudler, G., en "Les sources historiques de la Princesse de Clèves", Revue du seizième siècle, II (1914), 92-131 y 289-321.

- "La couleur historique dans la Princesse de Clèves", Revue du seizième siècle, 5 (1917-18), 1-20.

Craveri, B., La cultura de la conversación, Biblioteca Ensayo, Siruela, 2003. 
FARET, N., L'honneste homme ou l'art de plaire à la court, Les Presses Universitaires de France, Paris, 1925.

Fayette, Mme de La, vid. Magne.

Festugik̀re, "Ginés Pérez de Hita. Sa personne, son œuvre", Bulletin Hispanique, 46 (1944), 145-183.

Flores, J., Grimalte y Gradissa, ed. Pamela Waley, London, Tamesis Books, 1971.

Fosalba, E., ed. Abencerrajepastoril. Estudioyedición crítica, Barcelona, Departamento de Filología Española, Universidad Autónoma de Barcelona, 1990.

- La Diana en Europa. Ediciones, traducciones e influencias, Seminari de Filologia

i Informàtica, Departament de Filologia Espanyola, Universitat Autònoma de Barcelona, Barcelona, 1994.

- «El Abencerraje como forma de vida en las guerras francesas de religión», Sin fronteras. Ensayos de Literatura Comparada en homenaje a Claudio Guillén, Castalia, Madrid, 1999, 105-111.

Fumaroli, M., "L'empire des femmes, ou l'esprit de joie» en La diplomatie de l'esprit. De Montaigne à La Fontaine, Collection Savoir: Lettres, Hermann Éditeurs des sciences et des arts, Paris, 1994, 321-339.

Holzbacher, A. M., pról. y trad. La Princesse de Clèves, en Letras Universales, Cátedra, 1987.

Laboureur, vid. Castelnau.

Lalanne, L., "Brantôme et La Princesse de Clèves», Paris, Société de l'Histoire de France, Nogent-Rotrou, Daupeley-Gouverneur, 1891.

- Brantôme, sa vie et ses écrits, Paris, Librairie Renouard, 1896.

Lettres portugaises (1669), Paris, Barbin, 1672-1673.

López Barrera, J., "Brantôme y el género bufo y grotesco de las «Rodomontadas espańolas» en la literatura francesa, de Joaquín López Barrera, Revista de Archivos, Bibliotecas y Museos, I (1923), pp. 3-28.

Magne, E. ed., Mme de Lafayette. Romans et Nouvelles, Librairie Garnier, París, 1939.

Marañón, G., Don Juan. Ensayos sobre el origen de su leyenda, Espasa-Calpe Argentina, Buenos Aires, 1946.

Martínez, C., prólogo a La Princesa de Clèves, Barcelona, Planeta, 1992.

Menestrier, C. F., Traité des tournois, ioustes, carrousels, et autres spectacles publics, Lyon, Jacques Muguet, 1669.

Mérimée, P., y Lacour., L., vid. Brantôme.

Morlet-Chantalat, Ch., "De la gloire héroïque à la constance amoureuse», La Clélie de Mademoiselle de Scudéry. De l'épopée à la gazette: un discours féminin de la gloire, Paris, Honoré Champion Éditeur, 1994, 161-177.

Morros, B., ed. La Quinta de Florencia, Parte II, Lérida, Prolope, Milenio, 1998.

PiA, P., vid. Brantôme.

Piccolomini, Eneas Silvio, Estoria muy verdadera de dos amantes, ed. Ines Ravasini, Dipartamento di Studi Romanzi, Università di Roma «La Sapienza», Testi, Studi e Manuali, 19, Bagatto Libri, 2003. 


\section{BULLETIN HISPANIQUE}

Pingaud, B., Mme de La Fayette, Escrivains de Toujours, Seuil, 1997.

Poizat, V., La véritable Princesse de Clèves, Paris, la Renaissance du Livre, 1920.

Princesse de Clèves, vid. Magne.

Rousset, J., Leurs yeux se rencontrèrent. La scène de première vue dans le roman, Paris, José Corti, 1984.

Reyner, G., Le roman sentimental avant l'Astrée, Paris, Armand Colin, 1971.

Riley, E. C., Teoria de la novela en Cervantes, Madrid, Taurus, 1971.

SAÏDE, vid. Magne.

San Pedro, D. de, Cárcel de Amor, ed. de Whinnom, Castalia, Madrid, 1985.

- Cárcel de Amor, ed. de Carmen Parrilla, Barcelona, Crítica, 1995.

ScÈve, M., La deplourable fin de Flamete [sic.]. Elegante inuention de Iehan de Flores Espaignol, traduicte en langue Francoyse. Nouuellement imprimee a Paris par Denys lanot, 1536.

SCudéry, $\mathrm{M}^{1 \mathrm{le}}$, Clélie, histoire romaine, second partie, Paris, 1655.

Schweitzer, J.W., Georges de Scudéry's Almahide. Authorship, Analysis, Sources and Structure, The Johns Hopkins Press y Oxford University Press, Paris, 1939.

Seco de Lucena, L., Origenes del orientalismo literario, Publicaciones de la Universidad Internacional Menéndez Pelayo, Santander, 1963.

Sevigné, Mme de., Correspondance, Paris, t. II, Bibliothèque de la Pléiade, Gallimard, 1974.

Tallemant des Réaux, Historiettes, Paris, Gallimard, Bibliothèque de la Pléiade, 1961.

Versini, L., Le roman épistolaire, Paris, Presses Universitaires de France, 1979.

VIGÉE, C., "La Princesse de Clèves et la tradition du refus», Critique, 1960, 723-754.

Voiture, Euvres, Paris, Charpentier, 1855.

YLLERA, A., «El relato intercalado en la novela del XVII: ¿Bello adorno o digresión enojosa?», El relato intercalado, ed. Claudio Guillén, Madrid, Fundación Juan March, Sociedad Española de Literatura General y Comparada, 1992, 109-117. 